\title{
Evolution of Magnifications in Endodontics: A Review
}

\author{
Madhumita Srinivasan ${ }^{1}$, Chakravarthy Dhanavel ${ }^{2}$, Jasmine Rayapudi ${ }^{3}$
}

\begin{abstract}
Over the past few decades, technological advances in endodontics have taken quantum leaps from conventional hand files to rotary system and from direct vision to magnification. The clarity and details are achieved by magnification devices such as orascope, dental loupes, and dental operating microscope. The details are very clear and revealing so that the endodontists can achieve precision in diagnosis, treatment procedures, and final assessment of procedure performed. Magnification technique is undergoing continuous advancements, allowing a better precision and quality standard. Microdentistry with its expanding possibility and increased clinical implication has now set a higher standard in patient care and in success rate of treatment procedures.
\end{abstract}

Keywords: Dental loupes, Dental operating microscope, Orascope.

Journal of Scientific Dentistry (2020): 10.5005/jp-journals-10083-0917

\section{INTRODUCTION}

The field of endodontics has witnessed significant technological advances over the past few decades. One area of advancement has been the evolution of endodontic visualization. The endodontists have always pursued to improve the vision of the operating field. The human naked eye with a resolving power of $0.2 \mathrm{~mm}$ is capable of distinguishing fine detail when an image is sharpened and enlarged to effectively magnify the area of interest for proper diagnosis and treatment of various dental pathologies., ${ }^{1,2}$ Magnification aids such as loupes, microscope, rod lens endoscope, and orascope help the endodontists to visualize the operating field beyond what can be perceived by the naked eye. Enhanced magnification and illumination help the clinician to identify accessory canals and other anatomical variations. ${ }^{3}$

Recently, in clinical dentistry, the dentist is now practising a higher level of microscope-assisted precision dentistry. ${ }^{2}$ The operating microscope has now fundamentally and radically changed the way endodontic surgeries can be performed. The microsurgical techniques have made possible and accessible results that were unimaginable before.

\section{Magnifying Glasses}

A magnifying glass is a double convex lens mounted in a frame with a handle (Fig. 1). A magnifying glass works by creating a magnified virtual image of an object behind the lens. This happens only when the distance between the lens and the object is shorter than the focal length of the lens. Magnifying glass has a focal length of 25 $\mathrm{cm}$ and an optical power of 4 diopters. Such a magnifier is available as a " $2 x^{\prime \prime}$ magnifier. ${ }^{3}$

\section{Dental Loupes}

Surgical loupes were used from 1870s. Binocular loupes were attached to spectacles in the 1900s. Magnification of loupes range from $2 \times$ to $6 \times$ (Fig. 2).

\section{Classification of Loupes}

- Based on the number of lens ${ }^{4}$

- Single lens
${ }^{1-3}$ Department of Conservative Dentistry and Endodontics, Indira Gandhi Institute of Dental Sciences, Sri Balaji Vidyapeeth, Puducherry, India

Corresponding Author: Madhumita Srinivasan, Department of Conservative Dentistry and Endodontics, Indira Gandhi Institute of Dental Sciences, Sri Balaji Vidyapeeth, Puducherry, India, Phone: +91 9500877555, e-mail: dr.madhumitasrinivasan1571995@gmail.com

How to cite this article: Srinivasan M, Dhanavel C, Rayapudi J. Evolution of Magnifications in Endodontics: A Review. J Sci Den 2020; 10(1):21-24.

Source of support: Nil

Conflict of interest: None

- Multiple lens

- Galilean optic loupes

- Prism loupes

- Based on the magnification system

- Flat plane, single lens loupes

- Surgical telescope with Galilean optical system

- Surgical telescope with Keplerian optical system

- Based on the design of loupes

- Through the lens loupes

- Flip-up loupes

\section{Advantages of Loupes}

It does not acquire much space, as it is small in size. It can be operated easily, no formal training is required. Surgeon's position is not restricted. Neither are they expensive as a microscope nor do they need higher maintenance. ${ }^{5}$

\section{Disadvantages of Loupes}

It does not provide depth perception due to the lack of stereoscopic view. Magnification beyond $5 \times$ is uncomfortable as it is heavy. Illumination is less when compared with microscope. Eyestrain, fatigue, and changes in vision can be experienced if poorly fixed loupes are used for longer time. ${ }^{5}$

(0) The Author(s). 2020 Open Access This article is distributed under the terms of the Creative Commons Attribution 4.0 International License (https://creativecommons. org/licenses/by-nc/4.0/), which permits unrestricted use, distribution, and non-commercial reproduction in any medium, provided you give appropriate credit to the original author(s) and the source, provide a link to the Creative Commons license, and indicate if changes were made. The Creative Commons Public Domain Dedication waiver (http://creativecommons.org/publicdomain/zero/1.0/) applies to the data made available in this article, unless otherwise stated. 


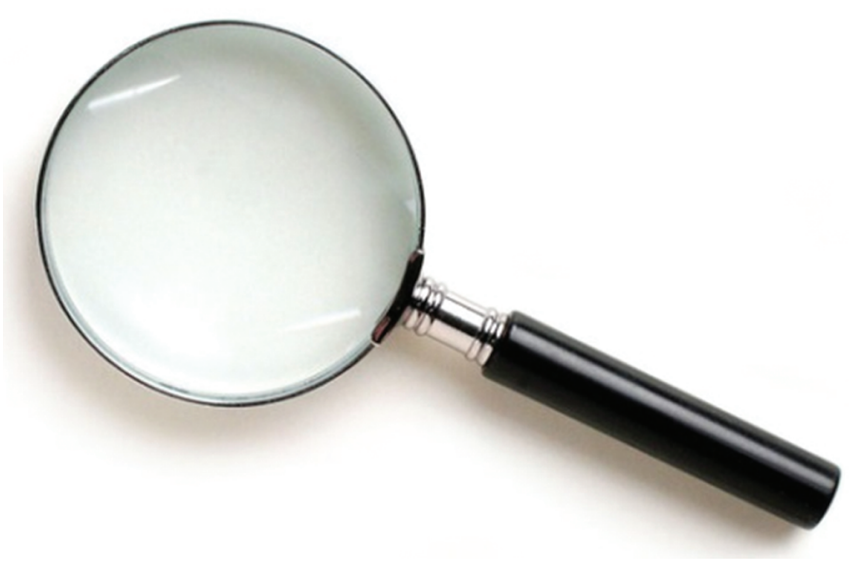

Fig. 1: Magnification lens

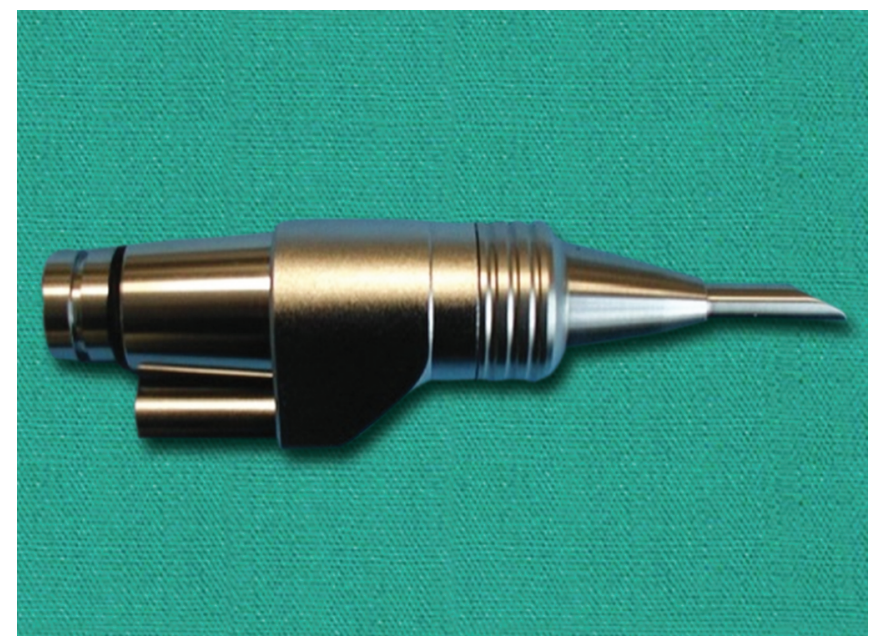

Fig. 3: Rod lens endoscope

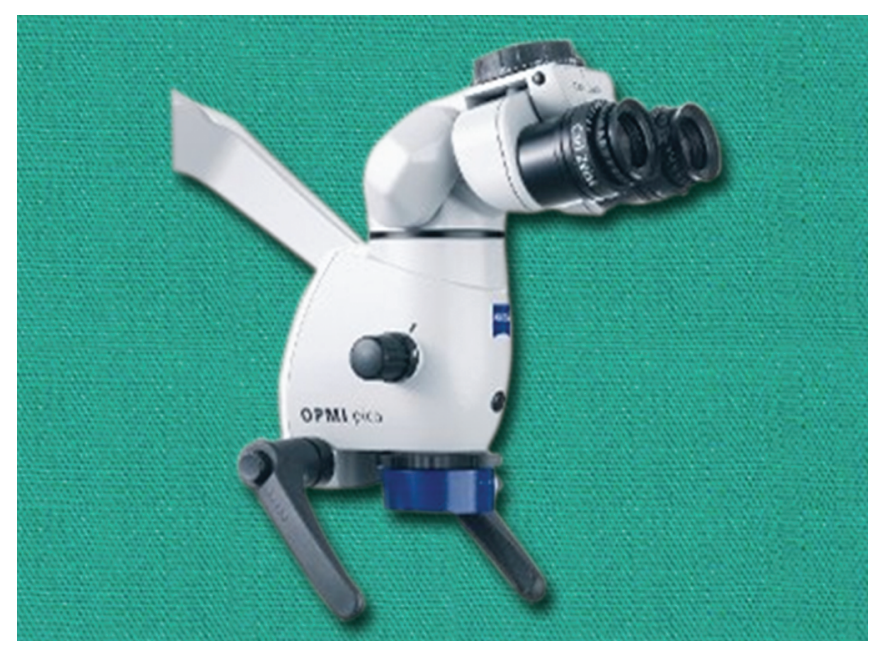

Fig. 5: Dental operating microscope

\section{Rod Lens Endoscope}

Rod lens endoscope provides greater magnification than loupes. It consists of rods of glass. It has a camera, a light source, and a monitor.

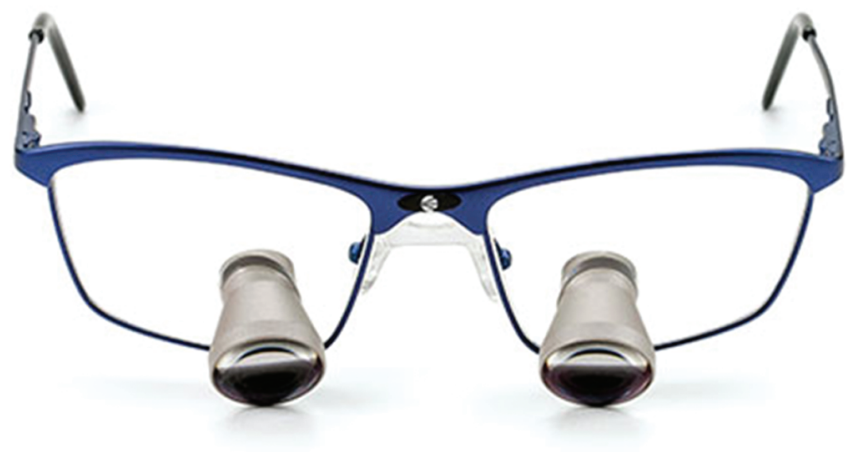

Fig. 2: Prism loupes

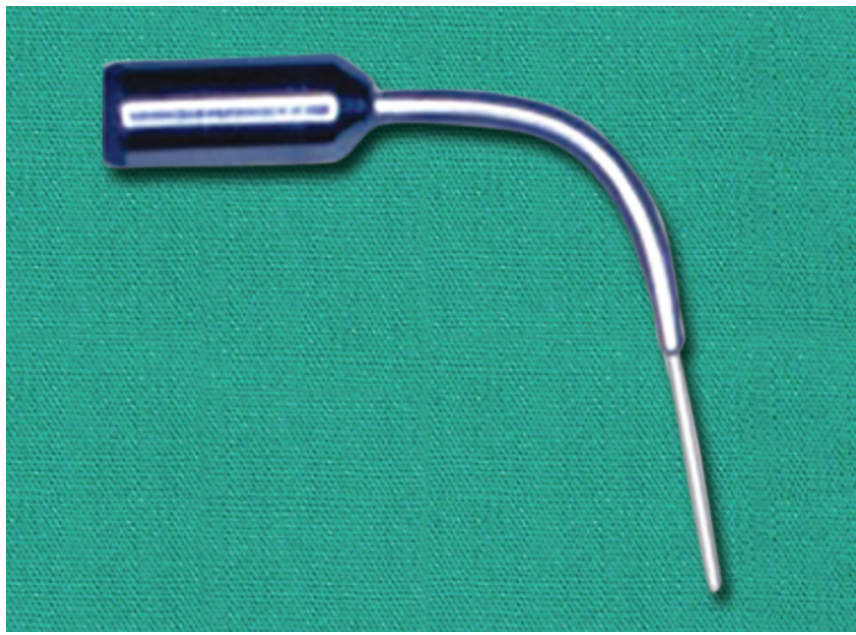

Fig. 4: Orascope

Disadvantage of rod lens endoscopy is that the instrument is rigid, so it cannot be used in visualizing curved root canals ${ }^{1,6}$ (Fig. 3).

\section{Orascope}

An orascope is a fiber optic endoscope designed for intracanal visualization (Fig. 4). Fiber optics is small, lightweight, and flexible plastic. The image quality has a direct correlation to the number of fibers and size of the lens used. Orascope is made of 10,000 parallel visual fibers. The visual fiber is between $3.7 \mu \mathrm{m}$ and $5.0 \mu \mathrm{m}$ in diameter. Orascope has a $0.8-\mathrm{mm}$ tip diameter, $0^{\circ}$ lenses, and a working portion of $15 \mathrm{~mm}$ in length. ${ }^{5,6}$

\section{Dental Operating Microscope}

The operating microscope has now fundamentally and radically changed the way endodontic procedures and surgeries can be performed (Fig. 5). The microscope provides better magnification from $3 \times$ to $30 \times$ and better illumination. It is beneficial for the clinician and the patients in terms of ergonomics, clear vision, better prognosis, minimal appointments, and economical. ${ }^{5}$ 
The operating microscope consists of three basic components

- The supporting structure

- The body of microscope

- The light source

\section{Supporting Structure}

The supporting structure stabilizes the microscope. It can be floor, ceiling, or wall mounted.

\section{Body of Microscope}

The body of microscope consists of

- Eyepieces

- Binoculars

- Magnification changer

- Objective lens

\section{Eyepiece}

The power of eyepiece determines magnification. Eyepieces are usually available in powers of $10 \times, 12.5 \times, 16 \times$, and $20 \times$. To adjust the accommodation of the lens of the eyes, diopter settings should range from -5 to +5 .

\section{Binocular}

The function of binoculars is to hold the eyepieces. It projects an intermediate image into the focal plane of the eyepieces. It comes in different focal lengths. Longer the focal length, the greater the magnification and the field of view is narrower.

\section{Magnification Changer}

It is situated within head of the microscope and is available as 3-, 5-, or 6-step manual changer, or a power zoom changer.

\section{Objective Lens}

Focal length of the objective lens determines the working distance between the microscope and the operating field. The focal length ranges from $100 \mathrm{~mm}$ to $400 \mathrm{~mm}$. Ideally, when the focal length is $200 \mathrm{~mm}$ there is $20 \mathrm{~cm} / 8$ inches of working distance. This distance is ideal for endodontic procedures. A layer of antireflective coating ensures absorption of minimum light to maintain the illumination of the operative field.

\section{Light Source}

The commonly available two light source systems are halogen light and xenon light.

Most common source is $100 \mathrm{~W}$ xenon halogen bulb. Its intensity is controlled by rheostat and cooled by a fan. Illumination and line of sight share the same axis, so that light is focused between the eyepieces and no shadows are visible.

\section{Magnification}

\footnotetext{
Total magnification ${ }^{7}$

$\mathrm{TM}=\mathrm{ft} / \mathrm{fo} \times \mathrm{Me} \times \mathrm{Mc}$

$\mathrm{TM}$, total magnification

$\mathrm{Ft}$, focal length of binocular lens

Fo, focal length of objective lens

Me, magnification of the eyepiece

Mc, magnification factor
}

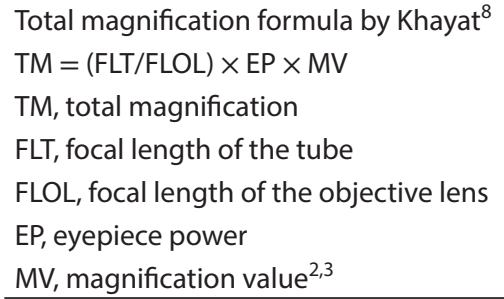

\section{ILLUMination}

Once the light reaches the operating field, it gets reflected back through the objective lens, magnification changer lenses, and the binoculars. It then exits to the operator's eyes as two separate beams of light. A stereoscopic effect produced by the separation of light beams. This enables the operator to visualize the depth of field. Illumination of the surgical microscope is coaxial with the line of sight. This allows the operator to visualize the surgical site without any shadows in the field. ${ }^{6,7}$

\section{Limitations of Magnification}

- Higher the magnification, the narrower will be the field of vision and the depth of field is smaller.

- As magnification increases, the effective aperture of the microscope is decreased, thus the amount of light that can reach the surgeon's eyes reduces and the surgical field appears darker. ${ }^{7}$

\section{Accessories for the Dental Operating MicRoscope}

- Bicycle handle attached at the bottom of the head facilitates movement during the procedures.

- Eyepiece with reticle field helps during video recording and photography.

- Observation ports can be added to the microscope by a beam splitter.

- Auxiliary monocular or articulating binoculars can also be added and can be used by a dental assistant.

- LCD screen provides a view to the patient as well as the assistant. ${ }^{9}$

\section{Advantages}

- Enhanced visualization

- Enhanced illumination

- Microfracture diagnosis

- Case documentation

- Co-observer tubes

- Improved quality and precision of treatment

- Enhanced ergonomics

\section{Disadvantages}

- Expensive

- Difficult to fit in a small operative room because of its size.

- Steep learning curve.

- Need for expertise by auxiliary staff and adaptation is quite difficult.

- Provides narrower field of vision. . $^{2,10,11}$ 


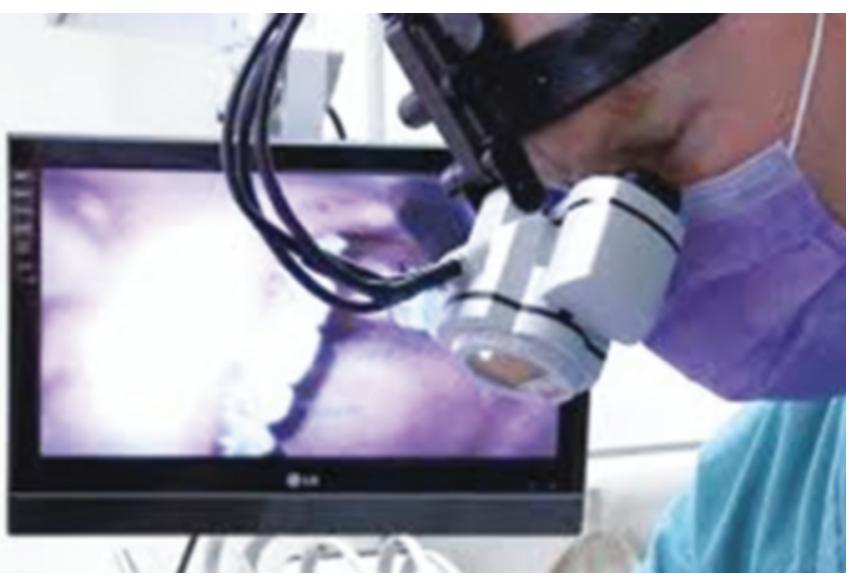

Fig. 6: Head-mounted dental operating microscope

\section{Recent Advancement in Magnification- Head-mounted Microscope}

It has a magnification range of $2.9 \times$ to $7.0 \times$. Its working distance is 11.81-27.56 inches. It is autofocus and has an integrated autofocus camera. It also has integrated light optics. Its field of view is 1.18-8.82 inches and has a shadow-free illumination (Figs 6 and 7).

\section{Conclusion}

The goal of magnification is to achieve the highest possible precision, better treatment, and prognosis. The use of magnification has enabled the endodontists to enhance their ability toward better diagnosis and treatment, to identify microfractures, to identify accessory canals, locate canal orifices, and identify anatomic variations in teeth and supporting structures. The trifecta of magnification-illumination-instrumentation without any doubt increases the quality of diagnosis and treatment results.

\section{References}

1. Dingra A, Nagar N. Recent advances in endodontic visualization: a review. J Dent Med Sci 2014;13(1):15-20.

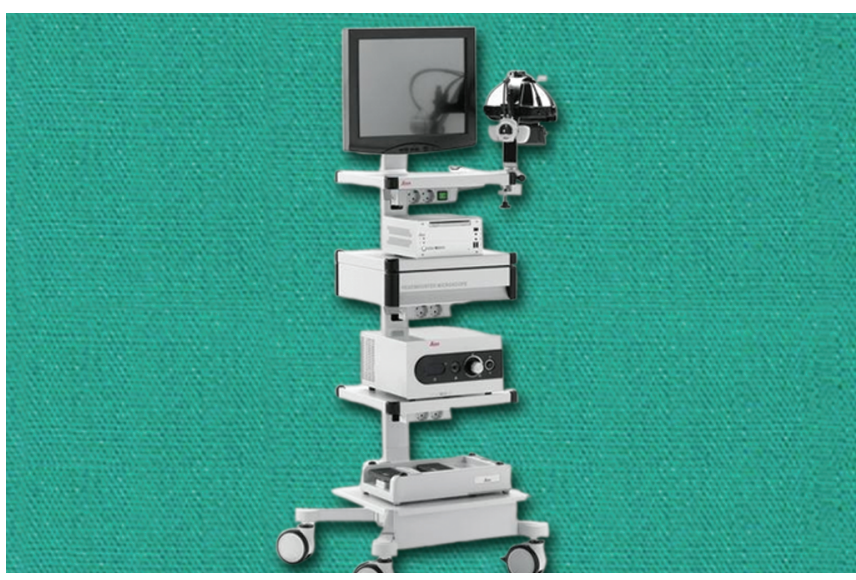

Fig. 7: Full unit of head-mounted operating microscope

2. Sachan S, Srivastava I, Pandey D. Magnification in endodontics. J Dent Med Sci 2016;15(6):63-68.

3. Das UK, Das S. Dental operating microscope in endodontics - a review. IOSR J Dent Med Sci 2013;15(6):01-08.

4. Carr GB, Murgel CA. The use of operating microscope in endodontics. Dent Clin North Am 2010;54(2):191-214. DOI: 10.1016/ j.cden.2010.01.002.

5. Singla MG, Girdhar D, Tanwar U. Magnification in endodontics: a review. Indian J Conserv Endod 2018;3(1):1-5. DOI: 10.18231/24568953.2018.0001.

6. Bahcall JK. Visualization in endodontics. Eur J Gen Dent 2013;2(2): 96-101. DOI: 10.4103/2278-9626.112303.

7. Shetty S, Tejaswi S. Magnification. An endodontic review. J Adv Clin Res Insights 2018;5:178-182. DOI: 10.15713/ins.jcri.239.

8. Khayat BG. The use of magnification in endodontic therapy: the operating microscope. Pract Periodont Aesthet Dent 1998;10(1):137-144.

9. Rubinstein $\mathrm{R}$. The anatomy of the surgical, operating microscope and operating positions. Dent Clin North Am 1997;41(3):391-413.

10. Low JF, Dom TNM, Baharin SA. Magnification in endodontics: a review of its application and acceptance among dental practitioners. Eur J Dent 2018;12(4):610-616. DOI: 10.4103/ejd.ejd_248_18.

11. Hegde R, Hegde V. Magnification-enhanced contemporary dentistry: getting started. J Interdiscip Dent 2016;6(2):91-100. DOI: 10.4103/2229-5194.197695. 